\title{
KINERJA PELAYANAN BARANG DI PELABUHAN UMUM GRESIK
}

\section{PERFORMANCE OF GOODS SERVICE IN GRESIK'S GENERAL PORT}

\author{
M. Rum Raekhan ${ }^{1}$, Ludfi Djakfar², Alwafi Pujiraharjo ${ }^{3}$ \\ 1,2,3 Dosen / Jurusan Teknik Sipil / Fakultas Teknik / Universitas Brawijaya \\ J1. M.T. Haryono No. 167, Malang-65145, Jawa Timur \\ Email: han.rey99@yahoo.co.id
}

\begin{abstract}
The volume of loading and unloading of goods at Gresik Public Port is increasing year by year. The length of the loading and unloading process has an effect on the length of the ship's round time turn and also the high operational costs. The amount of time that is still wasted when the ship is already in mooring causes the ship's effective time to do the loading and unloading process. Therefore, the purpose of this study is to determine the loading and unloading performance at Gresik Public Port, especially at Pier 265, Dry Bulk Pier and Pier 70 and the causes of idle time. In looking at the existing level of loading and unloading performance standards are set by the Director General of Transportation. The level of satisfaction and the importance of the variables related to loading and unloading are also measured by the user's perception. To analyze the existing performance and to identify the factors that cause idle time, descriptive analysis method is used, while to analyze the level of importance and customer satisfaction on loading and unloading operational performance, the Importance Performance Analysis method is used. The results of the analysis of the existing performance of loading and unloading operations show that the average loading and unloading productivity and effective time: berthing time (ET: BT) of ships carrying out loading and unloading activities at Pier 265 are still not good and are below the performance standards has been determined, while the Dry Bulk Pier and Pier 70 enter good achievement criteria. Many factors that hinder the loading and unloading process and often cause idle time include damage to loading and unloading equipment, waiting for trucks, waiting for cargo, availability of unloading workers and weather problems. From the analysis of user satisfaction there are variables that are included in quadrant 1 and require priority handling, which according to service users is of high importance but its performance is still unsatisfactory, including the length of time in the loading and unloading process, stacking capacity, truck readiness, port cleanliness and problems lighting.
\end{abstract}

Keywords: Descriptive Analysis; Loading and Unloading; Performance; IPA.

\begin{abstract}
Abstrak
Volume bongkar muat barang di Pelabuhan Umum Gresik dari tahun ke tahun semakin meningkat. Lamanya proses bongkar muat barang berpengaruh terhadap lamanya turn round time kapal dan juga tingginya biaya operasional. Banyaknya waktu yang masih terbuang saat kapal sudah berada di tambatan menyebabkan rendahnya waktu efektif kapal dalam melakukan proses bongkar muat. Oleh karena itu tujuan penelitian ini adalah mengetahui kinerja bongkar muat di Pelabuhan Umum Gresik khususnya pada Dermaga 265, Dermaga Curah Kering dan Dermaga 70 serta penyebab terjadinya idle time. Dalam melihat tingkat kinerja bongkar muat eksisting digunakan standar yang telah ditetapkan oleh Dirjen Hubla. Tingkat kepuasan dan kepentingan variabel-variabel terkait bongkar muat juga diukur dari persepsi pengguna. Untuk menganalisa kinerja eksisting dan untuk mengidentifikasi faktor yang menyebabkan idle time digunakan metode analisis deskriptif sedangkan untuk menganalisis tingkat kepentingan dan kepuasan pelanggan terhadap kinerja operasional bongkar muat digunakan metode Importance Performance Analysis. Hasil analisis kinerja eksisting operasional bongkar muat menunjukkan bahwa rata-rata produktivitas bongkar muat dan efektifitas waktu efektif time:berthing time (ET:BT) dari kapal-kapal yang melakukan kegiatan bongkar muat di Dermaga 265 masih kurang baik dan berada di bawah standar kinerja yang telah ditetapkan, sedangkan Dermaga Curah Kering dan Dermaga 70 masuk kriterria pencapaian yang baik. Faktor yang banyak menghambat proses bongkar muat dan sering menyebabkan idle time diantaranya kerusakan alat bongkar muat, menunggu truk, menunggu muatan, ketersediaan tenaga kerja bongkar muat
\end{abstract}


dan masalah cuaca. Dari analisis kepuasan pengguna didapatkan variabel-variabel yang masuk dalam kuadran 1 dan memerlukan prioritas penanganan, yang menurut pengguna jasa tingkat kepentingannya tinggi namun performanya masih belum memuaskan, diantaranya lamanya waktu dalam proses bongkar muat, kapasitas lapangan penumpukan, kesiapan truck, kebersihan pelabuhan dan masalah penerangan.

Kata kunci: Analisis Deskriptif; Bongkar Muat; Kinerja; IPA.

\section{PENDAHULUAN}

Dalam laporan yang dirilis oleh Bank Dunia tahun 2014, Indonesia menempati peringkat ke 52 Logistic Performance Index dan menempatkan kualitas layanan logistik di Indonesia di bawah negara-negara tetangga seperti Singapura, Malaysia, Thailand dan Vietnam.

Pelayanan angkutan barang menggunakan transportasi laut menjadi salah satu indikator yang memerlukan perhatian. Dengan bertumbuhnya jumlah bongkar muat yang ada di Pelabuhan Gresik, untuk mengoptimalkan efisiensi waktu dalam proses bongkar muat perlu ditingkatkan mengingat lamanya proses bongkar muat di pelabuhan berimplikasi pada lamanya turn round time sebuah kapal yang tentunya membuat biaya operasional kapal semakin mahal.

Sebagai pelabuhan yang diusahakan, Pelabuhan Gresik mempunyai kunjungan kapal yang cukup tinggi, optimalisasi waktu dalam menangani proses bongkar muat diharapkan dapat memperbaiki kinerja bongkar muat. Untuk mengetahui penyebab yang mempengaruhi lamanya proses bongkar muat dan sejauh mana pencapaian kinerja bongkar muat di Pelabuhan Umum Gresik perlu dilakukan kajian kinerja bongkar muat serta mengidentifikasi faktor-faktor yang menjadi penyebab lamanya proses bongkar muat.

Penelitian ini bertujuan untuk engetahui tingkat kinerja operasional bongkar muat Pelabuhan Umum Gresik; mengetahui penyebab yang menghambat kecepatan proses bongkar muat; dan mengetahui tingkat kepuasan pengguna jasa terhadap layanan operasional bongkar muat di Pelabuhan Umum Gresik.

\section{Kinerja Bongkar Muat}

Kinerja adalah hasil seseorang secara keseluruhan selama periode tertentu didalam melaksanakan tugas, seperti standar hasil kerja, target atau sasaran atau kriteria yang telah ditentukan terlebih dahulu dan telah disepakati bersama (Rivai dan Basri, 2004). Dalam Keputusan Dirjen Hubla No. UM.002/38/18/DJPL-11 tentang Standar Kinerja Pelayanan Operasional Pelabuhan, Kinerja pelayanan operasional adalah hasil kerja terukur yang dicapai pelabuhan dalam melakukan pelayanan kapal, barang dan utilisasi fasilitas dan alat dalam periode waktu dan satuan tertentu. Standar kinerja pelayanan operasional adalah standar hasil kerja dari tiaptiap pelayanan yang harus dicapai oleh operator terminal/pelabuhan dalam pelaksanaan pelayanan jasa kepelabuhanan termasuk dalam penyediaan fasilitas dan peralatan pelabuhan. Dalam Peraturan Menteri Perhubungan No. 60 Tahun 2014 tentang Penyelenggaraan Dan Pengusahaan Bongkar Muat Barang Dari dan ke Kapal, dijelaskan bahwa dalam proses bongkar muat meliputi 3 (tiga) kegiatan pokok yaitu stevedoring, cargdooring dan receiving/delivery. Penanganan muatan setelah dibongkar dari kapal dapat dilakukan dengan cara langsung diangkut dengan angkutan darat ke tempat tujuan, disimpan digudang atau lapangan penumpukan atau diangkut dengan kapal lain menuju tempat tujuan terakhir. Dalam sistem bongkar muat dikenal dua macam system operasional yaitu dengan cara truck lossing dan dengan cara penimbunan.

\section{Importance Performance Analysis}

Tujuan dari metode IPA adalah untuk mengukur hubungan antara persepsi konsumen dan prioritas peningkatan kualitas produk/ jasa yang dikenal pula sebagai analisis kuadran (Latu \& Everett, 2000). Metode IPA telah diterima secara umum dan sering digunakan pada berbagai bidang kajian karena kemudahan untuk diterapkan dan hasil tampilan analisa yang memudahkan usulan perbaikan kinerja (Martinez, 2003).

Dalam penelitian terdahulu yang dilakukan oleh Saikudin, 2014 variabel yang dianalisa terkait dengan pelayanan bongkar muat di pelabuhan adalah sebagai berikut; adanya 
fasilitas dan peralatan bongkar muat, tempat parkir, kapasitas dan kondisi dermaga, jarak dermaga dengan lapangan penumpukan, kapasitas dan kondisi lapangan penumpukan, akses gudang dengan dermaga, akses dermaga dengan jalan raya, kapasitas gudang, akses gudang dengan jalan raya, kebersihan pelabuhan, penerangan, lamanya pemrosesan dokumen bongkar muat, biaya pengurusan dokumen, tingkat pelayanan petugas pelabuhan, respon petugas atas keluhan pengguna jasa, ketersediaan informasi, kemampuan petugas, keamanan di pelabuhan. Sedangkan dari hasil observasi di lapangan didapati variabel-variabel yang juga mempengaruhi kinerja operasional adalah lamanya waktu untuk bongkar muat dan kesiapan armada ekspedisi muatan kapal laut.

\section{METODE PENELITIAN}

Penelitian ini dilakukan di Pelabuhan Umum Gresik khusunya di Dermaga 265, Dermaga Curah Kering dan Dermaga 78 sebagaimana ditampilkan dalam Gambar 1.

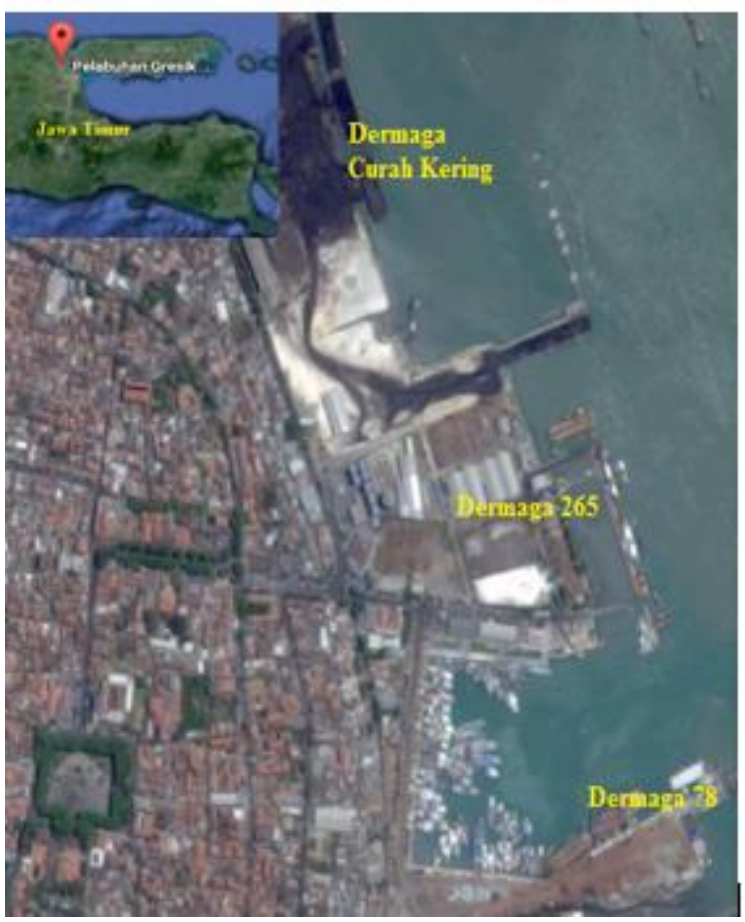

Gambar 1. Lokasi Penelitian

Metode pengumpulan data dalam penelitian ini dibagi menjadi dua, yaitu metode pengumpulan data primer dan data sekunder. Metode pengumpulan data primer dilakukan dengan menggunakan angket/ kuesioner dan wawancara yang dilakukan kepada pengguna jasa layanan bongkar muat yaitu pengurus keagenan kapal yang mewakili perusahaan pelayaran yang kapalnya melakukan bongkar muat di Pelabuhan Gresik. Hasil kuisioner ini digunakan untuk mengetahui tingkat kepentingan dan kinerja dari masing-masing variabel dalam kuisioer. Data sekunder yang dibutuhkan meliputi data jumlah kunjungan kapal, jenis komoditas bongkar muat, data tentang fasilitas pelabuhan dan data terkait proses bongkar muat kapal. Dari data yang telah diperoleh kemudian dilakukan analisis dengan menggunakan metode Importance Performance Analysis dan Quality Function Deployment. Selengkapnya tahapan penelitian ini ditampilkan dalam Gambar 2.

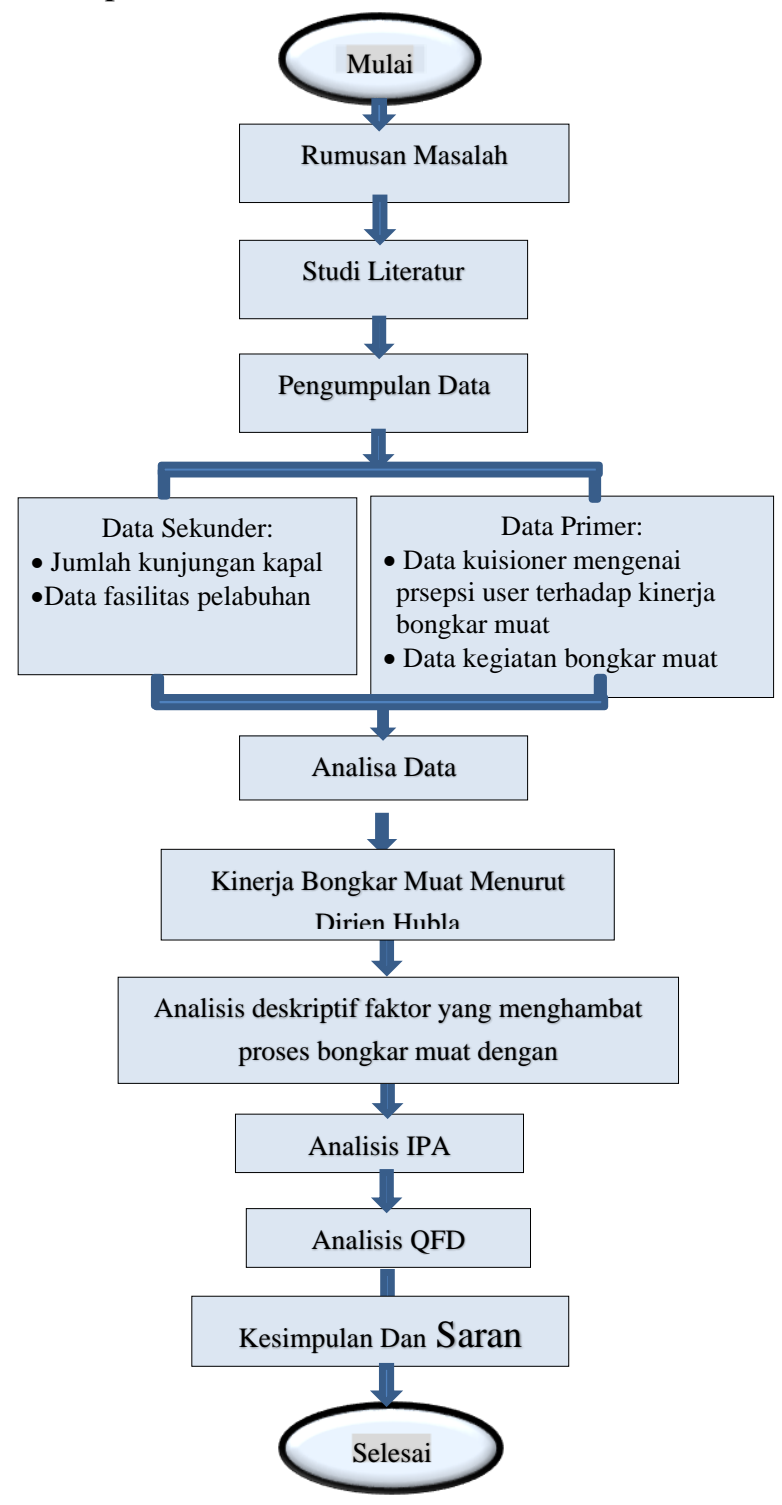

Gambar 2. Diagram alir penelitian 
HASIL DAN PEMBAHASAN

\section{Kinerja Bongkar Muat Berdasarkan SK Dirjen Hubla}

Dalam pembahasan ini kinerja bongkar muat yang dilakukan pada dermaga 265 yang banyak melakukan kegiatan bongkar muat bag cargo, dermaga Curah Kering yang melakukan bongkar muat curah kering dan dermaga 78 yang melakukan bongkar muat kayu log dan barang konstruksi. Berdasarkan standar kinerja dalam Surat Keputusan Direktur Jenderal Perhubungan Laut nomor UM.002/38/18/DJPL-11, aspek-aspek yang terkait dengan kinerja bongkar muat diantaranya produktivitas bongkar muat yang diukur dalam satuan ton/gang/jam $(\mathrm{t} / \mathrm{g} / \mathrm{j})$ dan efektifitas waktu bongkar muat kapal selama berada di tambatan yang diukur dalam satuan persen (\%). Untuk pencapaian kinerja pelayanan operasional dari masing-masing indikator ET:BT dan kinerja bongkar muat ditentukan sebagai berikut :

a. apabila nilai pencapaian diatas nilai standar kinerja pelayanan operasional yang ditetapkan, dinyatakan baik;

b. apabila nilai pencapaian diatas $90 \%$ sampai dengan $100 \%$ dari nilai standar kinerja pelayanan operasional yang ditetapkan, dinilai cukup baik.

c. apabila nilai pencapaian kurang dari $90 \%$ dari nilai standar kinerja pelayanan operasional yang ditetapkan, dinilai kurang baik.

Tabel 1 Kinerja Bongkar Muat

\begin{tabular}{|c|c|c|c|c|c|c|}
\hline No. & Dermaga & Jenis layanan & Standar & satuan & capaian & Keterangan \\
\hline \multirow[t]{2}{*}{1} & $\begin{array}{l}\text { Dermaga 265 } \\
\text { (bag cargo) }\end{array}$ & $\begin{array}{l}\text { Produktivitas } \\
\text { Bongkar muat }\end{array}$ & 35 & $\mathrm{t} / \mathrm{g} / \mathrm{j}$ & 31,20 & Kurang Baik \\
\hline & & ET:BT & 70 & $\%$ & 50,5 & Kurang Baik \\
\hline \multirow[t]{2}{*}{2} & $\begin{array}{l}\text { Dermaga Curah } \\
\text { Kering }\end{array}$ & $\begin{array}{l}\text { Produktivitas } \\
\text { Bongkar muat }\end{array}$ & 100 & $t / j$ & 231,44 & Baik \\
\hline & & ET:BT & 70 & & 72,49 & Baik \\
\hline \multirow[t]{2}{*}{3} & $\begin{array}{l}\text { Dermaga } 78 \\
\text { (general cargo) }\end{array}$ & $\begin{array}{l}\text { Produktivitas } \\
\text { Bongkar muat }\end{array}$ & 30 & $t / g / j$ & 57,44 & Baik \\
\hline & & ET:BT & 70 & $\%$ & 75,99 & Baik \\
\hline
\end{tabular}

Dari Tabel 1 terlihat bahwa efektifitas untuk dermaga 265 masih kurang baik, hal ini antara lain dipengaruhi terjadinya idle time saat proses bongkar muat. Adapun hal-hal yang banyak menyebabkan idle time pada Dermaga 265 dan dermaga 78 disajikan dalam Tabel 2 dan Tabel 3.

Tabel 2 Penyebab idle time Dermaga 265

\begin{tabular}{lccccr}
\hline & \multicolumn{5}{c}{ Statistik Deskriptif } \\
& $\begin{array}{c}\mathrm{N} \\
(\mathrm{kapal})\end{array}$ & $\begin{array}{c}\text { Minimal } \\
(\mathrm{jam})\end{array}$ & $\begin{array}{c}\text { Maksimal } \\
(\mathrm{jam})\end{array}$ & $\begin{array}{c}\text { Rerata } \\
(\mathrm{jam})\end{array}$ & Std. Deviasi \\
\hline Menunggu Truck & 39 & .00 & 8.00 & 2.1987 & 2.09211 \\
Kerusakan Alat B/M & 39 & .00 & 4.00 & .6372 & 1.00116 \\
Masalah TKBM & 39 & .00 & 2.00 & .2564 & .54858 \\
Menunggu Muatan & 39 & .00 & 12.10 & 3.2167 & 3.24563 \\
Cuaca & 39 & .00 & 4.00 & .6846 & 1.24405 \\
Valid N (listwise) & 39 & & & & \\
\hline
\end{tabular}


Tabel 3 Penyebab idle time Dermaga 78

\begin{tabular}{lrrrrr}
\hline & \multicolumn{5}{c}{ Statistik Deskriptif } \\
& $\mathrm{N}$ & Minimum & \multicolumn{1}{c}{ Maximum } & \multicolumn{1}{c}{ Rerata } & \multicolumn{1}{c}{ Std. Deviasi } \\
\hline Menunggu truck & 42 & .00 & 11.50 & 1.4869 & 2.57412 \\
Kerusakan alat & 42 & .00 & 10.50 & .5476 & 1.73138 \\
Masalah TKBM & 42 & .00 & 5.00 & .6548 & 1.18161 \\
Menunggu muatan & 42 & .00 & 6.00 & .6429 & 1.54322 \\
Lainnya & 42 & .00 & 16.30 & .7214 & 4.08994 \\
Valid N (listwise) & 42 & & & & \\
\hline
\end{tabular}

\section{Kinerja Bongkar Muat Berdasarkan Analisis IPA}

Untuk mengetahui persepsi user terhadap tingkat kepentingan dan tingkat kinerja bongkar muat dilakukan analisis dengan menggunakan metode analisis Importance Performance Analysis (IPA). berdasarkan data rata-rata tingkat kinerja dan kepentingan yang didapatkan dari kuisioner yang diisi oleh reponden. Yang kemudian dibuat diagram kartesius analisis IPA, dengan rata-rata tingkat kinerja sebagai sumbu $\mathrm{x}$ dan kepentingan sebagai sumbu y.

Tabel 4 Rata-rata tingkat kepentingan dan kinerja

\begin{tabular}{clcc}
\hline No. & \multicolumn{1}{c}{ Uraian } & Kepentingan & Kinerja \\
\hline 1 & Kecepatan dalam melakukan proses bongkar muat & 4.053 & 2.711 \\
2 & Kesiapan armada EMKL (truck) & 3.789 & 2.842 \\
3 & Ketersediaan fasilitas dan peralatan bongkar muat barang & 3.737 & 3.211 \\
4 & Jarak dermaga dengan lapangan penumpukan & 3.711 & 3.158 \\
5 & Kondisi dan kapasitas lapangan penumpukan & 3.684 & 2.842 \\
6 & Aksesibilitas gudang ke dermaga & 3.368 & 3.053 \\
7 & Aksesibilitas dermaga dengan jalan raya & 3.737 & 3.184 \\
8 & Gudang yang luas untuk penampungan barang & 3.158 & 2.842 \\
9 & Aksesibilitas gudang dengan jalan raya & 3.421 & 3.053 \\
10 & Kebersihan area pelabuhan & 3.605 & 2.921 \\
11 & Penerangan di pelabuhan (malam hari) & 3.632 & 2.816 \\
12 & Waktu dalam pemrosesan dokumen bongkar muat & 3.158 & 3.105 \\
13 & Besaran biaya pengurusan dokumen & 3.000 & 2.921 \\
14 & Keramahan pelayanan petugas pelabuhan & 3.632 & 3.395 \\
15 & Tanggapan petugas atas keluhan pengguna jasa & 3.763 & 3.316 \\
16 & Kejelasan informasi tentang bongkar muat & 3.711 & 3.289 \\
17 & Ketrampilan dan kecakapan petugas & 3.421 & 3.526 \\
18 & Keamanan di lingkungan pelabuhan & 3.658 & 3.184 \\
19 & Ketersediaan area parkir kendaraan di pelabuhan & 3.632 & 3.184 \\
20 & Kondisi dermaga (lebar, kuat, panjang) & 3.763 & 3.342 \\
\hline
\end{tabular}

Dari hasil perhitungan tingkat kepentingan dan tingkat kinerja kemudian dituangkan dalam diagram kartesius sebagaimana dalam Gambar 1. 


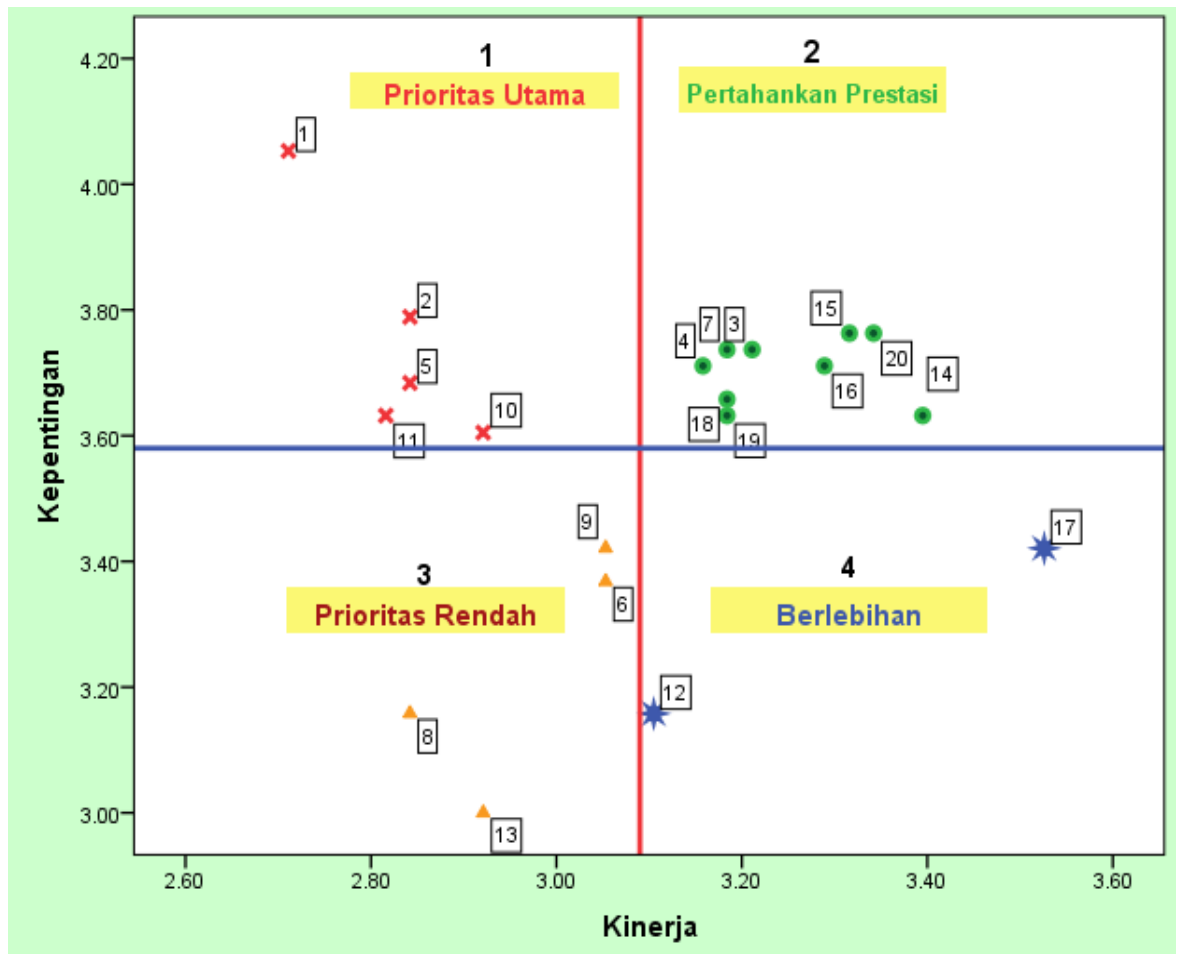

Gambar 1. Diagram Kartesius kinerja bongkar muat

\section{KESIMPULAN DAN SARAN Kesimpulan}

- Berdasarkan standar kinerja yang ditetapkan oleh Direktorat Jenderal Perhubungan Laut No. UM.002/38/18/DJPL-11, untuk produktivitas bongkar muat Dermaga 265 mencapai $31,20 \mathrm{t} / \mathrm{g} / \mathrm{j}$ dari standar yang ditetapkan sebesar $30 \mathrm{t} / \mathrm{g} / \mathrm{j}$ dengan predikat cukup baik, sedangkan untuk waktu efektif mencapai $50,5 \%$ dari standar yang ditetapkan $70 \%$ dengan predikat kurang baik. Dermaga Curah Kering mencapai produktivitas 231,44 t/j dari standar yang ditetapkan sebesar $100 \mathrm{t} / \mathrm{j}$, waktu efektif $72,49 \%$ dari standar yang ditetapkan sebesat $70 \%$ dengan predikat baik. Dermaga 78 mencapai produktivitas sebesar 57,44 t/g/j dengan standar yang ditetapkan sebesar 30 $\mathrm{t} / \mathrm{g} / \mathrm{j}$ dengan predikat baik dan efektifitas waktu bongkar muatnya mencapai 75,99\% dengan predikat baik.

- Berdasarkan hasil analisis dengan menggunakan analisis deskriptif dapat diketahui bahwa waktu yang terbuang saat kapal berada di tambatan (idle time) dikarenakan keterlambatan truk, masalah tenaga kerja bongkar muat, keterlambatan muatan dan kondisi cuaca berpengaruh pada kecepatan proses bongkar muat.
- Dari hasil analisis IPA, variabel-variabel yang memerlukan perbaikan guna mencapai tingkat kinerja yang diharapkan user adalah variabel kecepatan proses bongkar muat, kesiapan armada, kapasitas lapangan

- penumpukan, kebersihan area pelabuhan serta penerangan malam hari.

- Untuk peningkatan kinerja bongkar muat serta menentukan prioritas penanganannya, dengan menggunakan metode Quallity Function Deployment didapatkan hasil bahwa urutan prioritasnya adalah memastikan kesiapan muatan untuk barang yang akan dimuat, memanfaatkan gudang secara optimal, memastikan kesiapan alat bongkar muat, menyediakan fresh gang untuk pelayanan 24 jam, memeperluas lapangan penumpukan, mempercepat pengangkutan barang yang ada dilapangan penumpukan, menambah lampu penerangan, memastikan kapal yang akan melakukan bongkar muat telah menunjuk perusahaan ekspedisi muatan kapal laut dengan jumlah armada yang cukup untuk melayani sesuai jumlah muatan kapal dan prioritas terakhir adalah peningkatan kebersihan area pelabuhan. 


\section{Saran}

a. Perlunya peningkatan koordinasi yang baik antara perusahaan pelayaran, perusahaan bongkar muat, perusahaan ekspedisi muatan kapal laut atau jasa pengurusan transportasi serta Kantor Kesyahbandaran Dan Otoritas Pelabuhan Greik.

b. Setiap perusahaan bongkar muat yang akan melakukan kegiatan harus menyerahkan informasi yang jelas tentang jumlah muatan, jenis kemasan, peralatan bongkar muat, jumlah gang yang akan dipakai, jumlah shift serta closing time (waktu yang dibutuhkan untuk melakukan bongkar muat) secara rinci, dan pengenaan sanksi terhadap perusahaan bongkar muat yang melampaui closing time yang telah ditentukan.

c. Pemeliharaan alat bongkar muat baik yang didarat maupun diatas kapal harus dilakukan secara berkala dan dilaporkan kepada Kantor Kesyahbandaran Dan Otoritas Pelabuhan, untuk menghindari idle time yang disebabkan kerusakan alat bongkar muat.

d. Penyediaan tenaga kerja bongkar muat yang cukup agar tersedia fresh gang untuk dapat melayani kegiatan bongkar muat 24 jam.

e. Memperluas lapangan penumpukan dan memberikan batasan waktu untuk penggunaan lapangan penumpukan agar kapasitas lapangan penumpukan bisa tetap memadai dalam mendukung kegiatan bongkar muat.

f. Untuk memperkecil idle time karena menunggu armada, perlu pertimbangkan untuk menggunakan gudang.

g. Perlu peningkatan pengawasan dan evaluasi oleh regulator yang dalam hal ini Kantor Kesyahbandaran Dan Otoritas Pelabuhan Kelas II Gresik terhadap produktivitas bongkar muat masing-masing kapal. Hal ini bisa dipantau melalui time sheet yang harus dilaporkan oleh tiap-tiap perusahaan bongkar muat yang melakukan kegiatan.

h. Bagi peneliti selanjutnya diharapkan bisa lebih mengkaji lebih mendalam lagi mengenai faktor-faktor yang mempengaruhi kinerja bongkar muat dari segi kedisiplinan, kesejahteraan dan profesionalitas tenaga kerja bongkar muat serta faktor perawatan peralatan bongkar muat.

\section{DAFTAR PUSTAKA}

Anonim. (2011). Surat Keputusan Direktur Jenderal PerhubuganLaut No. UM.002/38/18/DJPL-11 tanggal 5 Desember 2011 tentang Standar Kinerja Pelayanan Operasional Pelabuhan. Jakarta.

Anoim. (2014). Peraturan Menteri Perhubungan No. 60 tahun 2014 tentang Penyelenggaraan dan Pengusahaan Bongkar Muat Barang Dari dan ke Kapal. Jakarta.

The World Bank, (2014). Logistic Performance Index.

http://lpi.worldbank.org/international/sc orecard/radar/254/C/IDN/2014/C/MYS/ 2014\#chartarea.

Gultom, E. (2007). Refungsionalisasi Pengaturan Pelabuhan Untuk Meningkatkan Ekonomi Nasional. Jakarta: Raja Grafindo Perkasa.

Latu, T. M. (2000). Review of Satisfaction Research and Measurement Approaches. Departement of Conservation, Wellington, NewZealand.:

http://www.doc.govt.nz/Publications/00 4 Science-and-Research/Olderseries/PDF/IR183.pdf.

Martinez, C. L. (2003). Evaluation Report: Tools Cluster Networking Meeting \#1, CenterPoint Institute, Inc., Arizona. http://www.centerpointinstitute.org/.../ Networking\%20Meeting\%201_Evaluat ion\%20Report\%20FINAL.pdf.

Nasril. (2013). Peningkatan Pelayanan Bongkar Muat Dan Kapal di Pelabuhan Sunda Kelapa. Jakarta: Puslitbang Perhubungan Laut, Kementerian Perhubungan.

Saikudin. (2014). Kajian Kinerja Angkutan Barang Di Pelabuhan Tanjung Tembaga Kota Probolinggo. Malang: Pasca Sarjana Magister Teknik Sipil Universitas Brawijaya.

Triatmodjo, B. (2010). Perencanaan Pelabuhan. Yogyakarta: Beta Offset. 